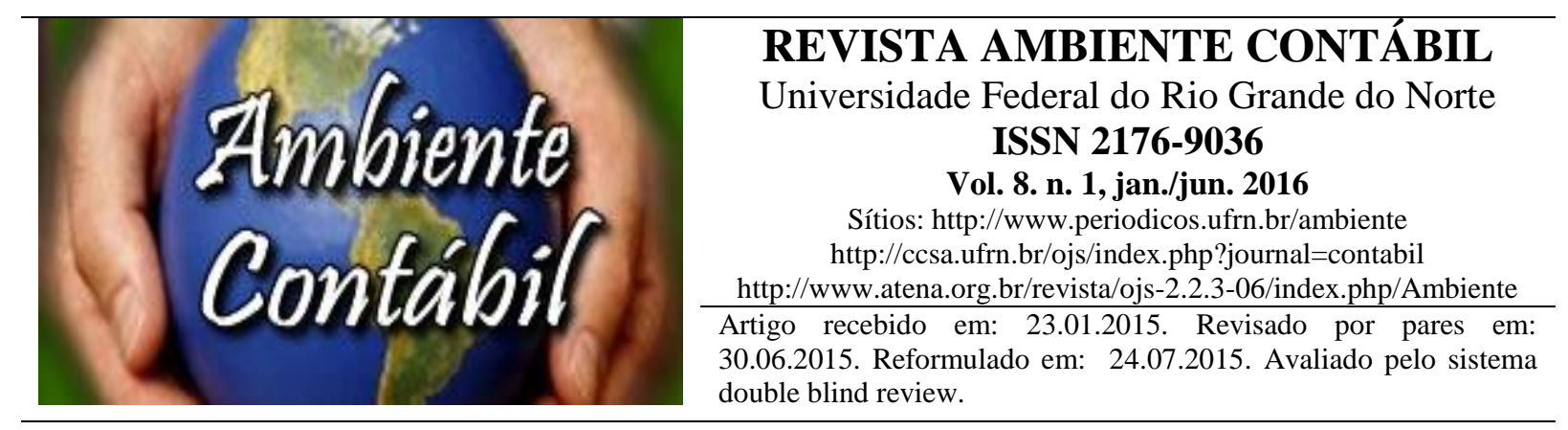

\title{
METODOLOGIAS DE CUSTEIO E PREÇO DE VENDA: UM ESTUDO SOBRE AS PRÁTICAS DOS EMPREENDIMENTOS ECONÔMICOS SOLIDÁRIOS
}

\section{COSTING METHODOLOGIES AND PRICING: A STUDY OF PRACTICES OF THE SOLIDARY ECONOMIC ENTERPRISES}

\section{METODOLOGÍA DE COSTOS Y FORMACIÓN DE PRECIOS: UN ESTUDIO DE LAS PRÁCTICAS DOS EMPRENDIMENTOS ECONÓMICOS SOLIDÁRIOS}

\author{
Autores \\ Rayanna Nayhara Oliveira do Nascimento \\ Graduada em Ciências Contábeis pela Universidade Federal Rural do Semi-Árido. Endereço: \\ Av. Francisco Mota, 572, Bairro Costa e Silva, Mossoró/RN, Brasil. CEP 59.625900 - Brasil. \\ E-mail: rayanna.oliveira88@gmail.com \\ Thaiseany de Freitas Rêgo \\ Graduada em Ciências Contábeis pela UFRN - Mestre em Ciências Contábeis pela \\ UnB/UFPB/UFRN. Professora da Universidade Federal do Semi-árido (UFERSA). \\ Doutoranda em Administração pela PUC-PR. Endereço: Av. Francisco Mota, 572, Bairro \\ Costa e Silva, Mossoró/RN, CEP 59.625-900 - Brasil. Telefone: (84) 8709-1842/ 9651-2423. \\ E-mail: thaiseany@yahoo.com.br

\section{Thiago Ferreira Dias} \\ Doutor em Administração pela Universidade Federal do Rio Grande do Norte. Endereço: \\ Campus da Universidade Federal do Rio Grande do Norte, Centro de Ciências Sociais \\ Aplicadas (CCSA), sala 11 (anexo $2^{\circ}$ andar) Lagoa Nova - CEP: 59.078-970 - Natal, RN - \\ Brasil. Telefone: (84) 3342-2288 ramal 182 \\ E-mail: tfdpe@yahoo.com.br
}

\section{RESUMO}

O estudo objetivou identificar quais são as metodologias de custeio e preço de venda adotadas pelos Empreendimentos Econômicos Solidários (EES) de Mossoró/RN para a formação do preço justo de seus produtos e serviços. Para tanto, utilizou-se de um estudo do tipo multicaso que se pauta na realização de entrevistas semiestruturadas e na análise de conteúdo. As entrevistas foram realizadas junto aos indivíduos que atuam no controle e na marcação do preço de venda dos artigos produzidos pelos EES. A apreciação das entrevistas foi pautada na análise de conteúdo, com o auxílio do software Atlas.ti (versão 5.0), o que permitiu a codificação e categorização dos diálogos. Considerando os mais conhecidos métodos de 
custeio (absorção, variável e por atividades) e formação do preço de venda, destaca-se que as práticas adotadas pela Acrevi são insuficientes para a determinação do preço justo de venda. Já no que concerne a Coopermups e o GMUPA, observa-se que se utilizam da gestão de mão de obra direta e indireta, da matéria-prima e materiais indiretos como medidas essenciais para a determinação do preço justo.

Palavras-chave: Gestão de custos. Formação do preço. Economia solidária. Preço justo.

\begin{abstract}
The study aimed to identify the pricing and costing methodologies adopted by solidary economic enterprises of Mossoró/RN to fair pricing of its products and services. To reach this objective, I used a case study, which consists in semi-structured interview and content analysis. The interviews were made with the individuals that act in the pricing and control of the sale price of the good produced by SEE. The interviews were based in content analysis, with the support of software Atlas IT (5.0 version), which permitted the codification and categorization of the dialogs. Considering the most known costing methods (absorption costing, variable costing and activity-based costing) and sales pricing, we concluded that the practices adopted by Acrevi are insufficient to fair pricing. Whereas the Coopermup and the GMUPA, it is observed that, they are used of labor management, input and indirect materials, as essential measures for the fair pricing.
\end{abstract}

Keywords: Cost management. Pricing; solidary economy. Fair price.

\title{
RESUMEN
}

El estudio pretende identificar qué metodologías de cálculo de costos y el precio de venta adoptada por las empresas económicas comprensivas (ve) de Mossoró/RN, para la formación del precio justo de sus productos y servicios. Para ello, se utilizó un estudio de tipo paralelo basado en entrevistas semiestructuradas y el análisis de contenido. Las entrevistas se realizaron con personas que actúan en el control y marcar el precio de venta de los artículos producidos por el ESS. La evaluación de las entrevistas se basó en el análisis de contenido, con la ayuda del software Atlas. TI (versión 5.0), que permite la codificación y categorización de los diálogos. Mientras que los más conocidos métodos de costes (absorción, variable y por actividades) y la formación del precio de venta, destacar las prácticas adoptadas por Acrevi son insuficientes para determinar el precio justo de venta. Ya en el Coopermups y el GMUPA, se observa lo uso de mano de obra directa e indirecta, materias primas y materiales indirectos como medidas esenciales para determinar el precio justo.

Palabras clave: Gestión de costes. La formación de precios. La economía solidaria. Precio justo.

\section{INTRODUÇÃO}

As crises e vulnerabilidades econômicas, vinculadas aos problemas de exclusão social, estimularam os indivíduos a desenvolverem os preceitos da Economia Solidária (Ecosol), que consiste em estabelecer relações econômico-sociais mais justas. França Filho (2001) aponta que essa perspectiva organizacional surge em meio às falhas dos mecanismos políticos. Seguindo esse entendimento, Dias $(2009$, p. 9) afirma que "a economia solidária busca não só atenuar as desigualdades sociais, mas, igualmente, abrir novas perspectivas e caminhos para outro olhar sobre a compreensão que se tem da economia".

Compreende-se que as experiências da Ecosol se materializam nos Empreendimentos Econômicos Solidários (EES). Segundo Schmitt (2010, p. 56), "ao mesmo tempo em que possuem elementos de crítica às formas de organização social dominantes, buscam garantir a sobrevivência de alguns milhares de trabalhadores no contexto de uma economia capitalista". 
Nessa perspectiva, a lógica dos EES segue aspectos divergentes do capitalismo, uma vez que aborda princípios da autogestão, solidariedade e cooperação.

Mundialmente, os EES têm se respaldado na reciprocidade e produção sustentável. Segundo dados do Sistema de Informação de Economia Solidária (SENAES-SIES, 2009), no Brasil há 21.859 EES, sendo 43,45\% deles situados na Região Nordeste. Dentre as motivações para constituição de empreendimentos dessa natureza, destaca-se a necessidade de estabelecimento de uma meta alternativa ao desemprego (SENAES-SIES, 2009). No Estado do Rio Grande do Norte (RN), estão registrados 817 EES, dos quais 37 localizam-se no Município de Mossoró, sendo 17 do tipo associações, 9 cooperativas, 10 grupos informais e 1 assume outra forma de organização.

Uma característica marcante dos EES consiste na aproximação do produtor ao consumidor, bem como no estabelecimento do preço justo que transcende o valor de troca. Asti (2007, p. 68) aponta que "o preço leva em consideração não apenas os aspectos econômicos das trocas, mas também os morais". Dessa forma, promove-se a capacidade de compra aos seus clientes sem a busca exacerbada pelo lucro, mas primando por uma remuneração digna e pela continuidade do empreendimento.

Partindo dos pontos observados, destaca-se a necessidade de identificar os métodos de custeio e o seu impacto na formação do preço justo. Segundo Miqueletto (2008, p. 14), é "fundamental que os gestores possuam o conhecimento da estrutura de custos de suas empresas para a adoção de políticas de formação de preço condizente com o mercado de atuação e, principalmente, com os objetivos organizacionais". Dessa forma, compreende-se que a partir da apuração dos custos envolvidos na produção e da utilização da contabilidade de custos, o preço justo pode ser determinado.

Considerando que a mutualidade, a qualidade de vida e o preço justo são princípios que norteiam a Ecosol, o presente estudo se propõe a responder a seguinte problemática: Quais as metodologias de custeio e preço de venda, adotadas pelos EES de Mossoró/RN, para a formação do preço justo de seus produtos e serviços? Nessa perspectiva, o estudo contribui para a identificação das práticas de gestão de custos utilizadas para a formação do preço justo dos produtos ou serviços oferecidos à sociedade.

\section{REFERENCIAL TEÓRICO}

\subsection{EMPREENDIMENTOS ECONÔMICOS SOLIDÁRIOS}

A Ecosol congrega empreendimentos que se baseiam na solidariedade e na promoção da igualdade entre os participantes, o que possibilita o desenvolvimento coletivo. Nessa concepção, Singer (2002, p. 10) afirma que "a aplicação desses princípios une todos os que produzem numa única classe de trabalhadores que são possuidores de capital por igual". $\mathrm{O}$ estudo de Santos, Mariano e Passanezi (2003) destaca que esses empreendimentos são formados por indivíduos e propõe uma visão diferenciada nas relações de trabalho e na sua forma de organização.

Gaiger (2003) frisa que as relações de trabalho estabelecidas em EES são distintas daquelas que envolvem empregador, empregado e pagamento de salário. Logo, observa-se que há uma concepção de igualdade nas relações de trabalho, como discutido no Fórum Brasileiro de Economia Solidária (FBES, 2003). A esse respeito Lisboa (2005, p. 109) afirma que "quando um empreendimento econômico abre mão da possibilidade de maximizar o lucro em função de uma perspectiva social e ecológica, então esta empresa tem uma postura solidária dentro da troca mercantil".

Dias (2011) aponta como princípios norteadores dos EES a questão da: autogestão, democracia, cooperação, apreciação da diversidade, emancipação, valorização dos aspectos 
locais e de aprendizado, justiça e sustentabilidade ambiental. Isso demonstra a particularidade desses empreendimentos em termos de benefícios e políticas de gestão.

Verenhitach (2007, p. 222) destaca que os EES seguem os preceitos de "posse coletiva dos meios de produção e distribuição; gestão democrática; repartição do excedente anual (sobras); não-remuneração do capital (cota-parte)". Nessa concepção, os mesmos acabam por constituir-se com a finalidade de propiciar a emancipação e superação das condições de desigualdades. Para Veronese e Guareschi (2005) o foco reside na quantidade e na qualidade do produto ou serviço oferecido, e não no lucro.

A proposta da Ecosol se reflete diretamente nos indivíduos que adotam os seus preceitos nos EES, principalmente em termos de renda. Outro ponto a se considerar é que os mesmos recebem pressões comerciais em um ambiente no qual há preponderância do capitalismo, o que reafirma a supremacia em termos de valorização. A mesma se traduz tanto em aspectos sociais inerentes ao trabalho coletivo e solidário, quanto em suas relações de negócio.

\subsection{METODOLOGIAS DE CUSTEIO}

A contabilidade de custos, segundo Maher (2001, p. 38), configura-se como um "ramo da contabilidade que mede, registra e relata informações sobre custos". Nesse aspecto, algumas metodologias foram constituídas com o intuito de auxiliar os gestores no processo de tomada de decisão, principalmente em termos de determinação do preço de venda. A adoção do método de custeio adequado (Quadro 1) tem se revelado como um elemento importante para a sobrevivência das organizações.

\section{Quadro 1 - Métodos de custeio}

\begin{tabular}{|c|c|c|}
\hline MÉTODO & FINALIDADE & FONTE \\
\hline \multirow{3}{*}{ Absorção } & Identificar os custos de produção, independentemente de ser fixo ou variável. & $\begin{array}{l}\text { Maher } \\
(2001)\end{array}$ \\
\hline & Apropriar os custos e gastos de produção aos produtos destinados a revenda. & $\begin{array}{l}\text { Martins } \\
(2003)\end{array}$ \\
\hline & $\begin{array}{l}\text { Atribuir um valor de custo ao produto, de forma direta ou indireta, mediante a } \\
\text { adoção de critérios de rateio. }\end{array}$ & $\begin{array}{l}\text { Wernke } \\
(2008)\end{array}$ \\
\hline \multirow{3}{*}{ Variável } & $\begin{array}{l}\text { Identificar a margem de contribuição de cada produto ao separar os custos fixos } \\
\text { e variáveis. }\end{array}$ & $\begin{array}{l}\text { Maher } \\
(2001)\end{array}$ \\
\hline & $\begin{array}{l}\text { Alocar aos produtos estocados e aos custos de produção apenas os custos } \\
\text { variáveis. }\end{array}$ & $\begin{array}{l}\text { Martins } \\
(2003)\end{array}$ \\
\hline & $\begin{array}{l}\text { Destinar aos produtos apenas os custos variáveis, enquanto que os custos fixos } \\
\text { ficam separados e são considerados como despesa do período. }\end{array}$ & $\begin{array}{l}\text { Wernke } \\
(2008)\end{array}$ \\
\hline \multirow{3}{*}{$\mathrm{ABC}$} & Vincular os recursos consumidos e custos incorridos às atividades e produtos. & $\begin{array}{l}\text { Maher } \\
(2001)\end{array}$ \\
\hline & $\begin{array}{l}\text { Permitir uma melhor visualização dos custos através da análise das atividades } \\
\text { executadas dentro da empresa e suas respectivas relações com os produtos. }\end{array}$ & $\begin{array}{c}\text { Martins } \\
(2003)\end{array}$ \\
\hline & $\begin{array}{l}\text { Analisar o comportamento dos custos por atividade e consumo de recursos, } \\
\text { sendo os mesmos rastreados por centros de atividades e produtos. }\end{array}$ & $\begin{array}{l}\text { Wernke } \\
(2008)\end{array}$ \\
\hline
\end{tabular}

Fonte: dados da pesquisa.

Salienta-se que cada método tem a sua peculiaridade e pode agregar informações distintas, conforme o interesse de seus usuários e o custo-benefício. A esse respeito, Martins (2003) comenta que a decisão sobre qual o modelo mais adequado depende do tipo de usuário e decisão a ser tomada. Desse modo, a demanda por informação e por potenciais stakeholders auxilia na determinação sobre qual dos métodos de custeio existentes é o mais adequado para fins legais e gerenciais.

Quando se trata da gestão do preço de venda, destaca-se a preocupação dos gestores com os parâmetros inerentes ao processo de produção e comercialização dos produtos e/ou 
serviços. Crepaldi (2009, p. 323) aponta o preço como sendo "a expressão do valor monetário dos benefícios que a empresa acredita que seus produtos ou serviços trazem aos seus clientes". Tal fato consiste na determinação de valor monetário aos produtos e serviços oferecidos, alinhando a sua aceitação com a demanda dos consumidores.

Pereira (2000) comenta que entre os mais diversos tipos de decisões gerenciais a questão da eficiência e eficácia são as mais importantes para garantir uma atuação satisfatória no mercado. Nessa perspectiva, torna-se vital para os gestores a identificação de um preço condizente com o público que se deseja atingir. A adoção de procedimentos que permitam a determinação do preço propicia aos gestores reconhecer a contribuição de cada um para a lucratividade e viabilidade do negócio.

\subsection{FORMAÇÃO DO PREÇO DE VENDA}

A determinação do preço de um produto ou serviço em processo de negociação costuma orientar as empresas para o uso racional dos recursos. Segundo Miqueletto (2008, p. 49), essa prática permite inserir "quantidades de produtos compatíveis com as reais tendências e capacidades de absorção da produção realizada". Desse modo, o custo e o preço de venda estimulam o planejamento e o controle da organização, tanto em termos de atenção ao cliente quanto de cobertura dos custos (GARRISON; NOREEN; BREWER, 2007).

No que diz respeito à formação do preço de venda, Martins (2003, p. 157) comenta que "os preços podem ser fixados: com base nos custos, com base no mercado ou com base numa combinação de ambos". Considerando essas perspectivas, a sua determinação precisa considerar informações sobre a gestão dos custos e os métodos de custeios. Destaca-se que, assim como os métodos de custeio, os critérios considerados para a formação do preço de venda (Quadro 2) de produtos ou prestação de serviços precisam ser analisados com atenção.

\begin{tabular}{|c|l|c|}
\multicolumn{2}{|c}{ Quadro 2 - Método de formação do preço de venda } \\
\hline MÉTODO & \multicolumn{1}{|c|}{ FINALIDADE } & FONTE \\
\hline \multirow{2}{*}{$\begin{array}{c}\text { Baseado no } \\
\text { custo }\end{array}$} & $\begin{array}{l}\text { Determinar o preço de venda, adicionando o lucro desejado por unidade aos } \\
\text { custos do produto. }\end{array}$ & $\begin{array}{c}\text { Martins } \\
(2001)\end{array}$ \\
\cline { 2 - 3 } & Constituir, a rigor, o piso do preço. & $\begin{array}{c}\text { Beulke e Bertó } \\
(2006)\end{array}$ \\
\hline \multirow{3}{*}{$\begin{array}{c}\text { Baseado no } \\
\text { mercado }\end{array}$} & $\begin{array}{l}\text { Definir o preço em mercados altamente competitivos a partir de fatores } \\
\text { mercadológicos (concorrentes, clientes, etc.). }\end{array}$ & $\begin{array}{c}\text { Horngren, } \\
\text { Datar e Foster } \\
(2004)\end{array}$ \\
\cline { 2 - 3 } & Precificar a partir de pesquisas de mercado. & $\begin{array}{c}\text { Kotler e Keller } \\
(2006)\end{array}$ \\
\hline \multirow{3}{*}{ Misto } & $\begin{array}{l}\text { Formar o preço-base, apoiado nos custos, e criticá-lo frente às } \\
\text { características de mercado (concorrentes, volume de vendas, condições de } \\
\text { entrega, qualidade, etc.) para fixação do preço mais apropriado. }\end{array}$ & $\begin{array}{c}\text { Bruni e Famá } \\
(2003)\end{array}$ \\
\cline { 2 - 3 } & $\begin{array}{l}\text { Determinar a conveniência de vender o produto, considerando os custos e o } \\
\text { preço que o mercado está disposto a pagar. }\end{array}$ & $\begin{array}{c}\text { Perez Júnior, } \\
\text { Oliveira e } \\
\text { Costa (2003) }\end{array}$ \\
\hline
\end{tabular}

Fonte: dados da pesquisa.

Além dos métodos supracitados, há ainda o preço orientativo (WERNKE, 2008) que se configura como uma prática interna capaz de analisar o custo unitário pelo markup (MIQUELETTO, 2008). Segundo Machado e Souza (2006), a formação do preço de venda requer a adoção de algum parâmetro ou referência para análise comparativa, com o intuito de torná-lo praticável. Dessa forma, evita-se a não absorção dos produtos/serviços oferecidos em função do preço da concorrência, sendo esse o ponto de partida para a gestão e definição do preço de venda.

Canever et al. (2012) comentam que a determinação do preço de venda requer um planejamento cuidadoso dos aspectos internos e externos da organização. Nessa conjuntura, a 
Revista Ambiente Contábil - ISSN 2176-9036 - UFRN - Natal-RN. v. 8. n. 1, p. 76 - 92, jan./jun. 2016

definição do preço de venda representa uma atribuição importante dos indivíduos que atuam no processo de planejamento e tomada de decisão. Isso porque, uma decisão sem os cuidados devidos pode levar a organização a se envolver em situações de risco, que acarretam perdas financeiras e desequilíbrios econômicos.

\subsection{PREÇO JUSTO}

A proposta dos empreendimentos da Ecosol consiste em atender ao bem-estar coletivo. Nessa perspectiva, o foco centra-se no tratamento igualitário dos participantes, bem como na promoção das condições de inclusão e desenvolvimento, mediante a oferta de produtos e serviços distintos daqueles oferecidos pela economia capitalista. Atenta a essas prerrogativas, a Carta de Princípios de Economia Solidária, divulgada no FBES (2003, p. 3) destaca que "a economia solidária promove o desenvolvimento de redes de comércio a preços justos".

Gomes (2003) aponta que um comércio justo, ético e solidário requer uma remuneração justa e digna para os indivíduos que produzem e consomem recursos. Logo, o princípio da "centralidade no ser humano" torna-se responsável pela satisfação e ganho bilateral entre as partes envolvidas na relação de negócio. Isso aponta a racionalidade e reciprocidade como uma ação contínua, que precisa ser conservada no processo de produção e consumo.

Oliveira, Araújo e Santos (2008, p. 215) comentam que o preço justo é "mutuamente acertado entre os produtores e compradores", sendo capaz de assegurar a sustentabilidade do produtor e de seus clientes. Para Asti (2007), esse só existe quando garante a qualidade de vida dos produtores e entrega algum produto ou serviço de valor para os interessados na relação. Sendo assim, o mesmo vai além do valor de troca, sendo capaz de satisfazer as necessidades de todos.

A prática do preço justo beneficia o consumidor final, uma vez que o "pagamento justo ao produtor leva em consideração a igualdade entre o trabalho de homens e mulheres" (ASTI, 2007, p. 78). Nessa perspectiva, observa-se que há certa diferença entre o preço de mercado e aquele estabelecido pela concorrência ou por seus clientes (MIQUELETTO, 2008). Em termos contábeis, o Conselho Federal de Contabilidade (CFC, 2010) ressalta que o preço justo configura-se como um processo de precificação caracterizado pelo consentimento das partes envolvidas, no qual não há favorecimentos.

Analisando a perspectiva do preço justo em comparação ao de mercado, destaca-se que o valor de um pode ser superior ao do outro. Nesse âmbito, o preço de mercado costuma ser superior por simbolizar um produto "convencional", que passa por atravessadores (FRANÇA FILHO, 2001). Já em ambientes que envolvem EES, a existência de uma produção fundamentada na qualidade costuma ser vendida diretamente ao consumidor por meio de processos simples.

A ideia do preço justo se propõe a "eliminar ao máximo o número de intermediários entre o produtor e o consumidor" (FRANÇA FILHO, 2001, p. 7). Isso se concretiza quando o EES produz e comercializa produtos/serviços sem a presença do atravessador, que costuma aproveitar-se do pequeno produtor. Nessa perspectiva, destaca-se a necessidade de se promover um preço justo, observando a necessidade de utilização de métodos de gestão adequados para minimizar os gastos com custos e despesas.

\section{METODOLOGIA DA PESQUISA}

O presente estudo é do tipo multicaso e se pauta no método qualitativo com o intuito de compreender as ações dos atores sociais (SILVA; MENEZES, 2005). Esse enquadramento se dá em razão da problemática e da necessidade de identificação das metodologias de custeio e de precificação adotadas pelos EES em Mossoró/RN. A referida abordagem observa o 
exame de elementos que influenciam os gestores do EES quanto aos fatores que condicionam o processo de formulação do preço de venda.

No que diz respeito aos objetivos, a pesquisa se classifica como do tipo descritiva. De modo que, para reunir informações sobre os integrantes dos EES estudados foram levantadas questões inerentes à caracterização dos empreendimentos, às dificuldades em relação ao preço justo, às peculiaridades dos EES e ao processo de gestão de custos. Quanto aos procedimentos, o estudo se utiliza das técnicas de observação e entrevistas semiestruturadas construídas com base nas discussões apresentadas no Quadro 3.

\section{Quadro 3 - Formação dos questionamentos}

\begin{tabular}{|c|l|c|}
\hline BLOCOS & \multicolumn{1}{|c|}{ FINALIDADE } & FONTE \\
\hline $\begin{array}{c}\text { Bloco 1: } \\
\text { Contextualização }\end{array}$ & $\begin{array}{l}\text { Indagar sobre aspectos gerais do empreendimento a fim de } \\
\text { compreender os fatos inerentes ao surgimento do EES, ramo } \\
\text { de atuação e dificuldades enfrentadas. }\end{array}$ & DIAS (2011). \\
\hline $\begin{array}{c}\text { Bloco 2: Processo } \\
\text { Produtivo }\end{array}$ & $\begin{array}{l}\text { Tratar sobre o processo produtivo e práticas de gestão no } \\
\text { setor, permitindo observar, por ramo de atuação, os métodos } \\
\text { de custeio e como ocorre a formação do preço de venda. }\end{array}$ & MOTTA (2000). \\
\hline $\begin{array}{c}\text { Bloco 3: Gestão } \\
\text { do Preço }\end{array}$ & $\begin{array}{l}\text { Identificar as práticas utilizadas para a formulação do preço } \\
\text { de venda e a adoção do preço justo. }\end{array}$ & $\begin{array}{c}\text { MOTTA (2000); } \\
\text { MIQUELETTO (2008); } \\
\text { DIAS (2011). }\end{array}$ \\
\hline
\end{tabular}

Fonte: dados da pesquisa.

Os tópicos criados para cada bloco nortearam o pesquisador na condução da entrevista, delegando ao processo um caráter mais informal e de menor rigidez. Nessa perspectiva, o processo de coleta ocorreu mediante o uso de um gravador, cuja utilização foi autorizada pelos entrevistados que eram parte do grupo gestor dos empreendimentos em estudo, totalizando 10 pessoas. A definição dos empreendimentos investigados (Quadro 4) é do tipo não probabilística. Esse recorte observou questões como localização, características do empreendimento e disponibilidade das equipes em participar do estudo, além da possibilidade de se estudar EES com formas organizacionais distintas.

Quadro 4 - EES participantes do estudo

\begin{tabular}{|c|c|c|c|}
\hline NOME DO EMPREENDIMENTO & LOCALIZAÇÃO & ANO & SETOR \\
\hline $\begin{array}{c}\text { Associação Comunitária Reciclando para a Vida } \\
\text { (Acrevi) }\end{array}$ & Mossoró/RN & 1999 & Serviço/Urbano \\
\hline Grupo Mulheres Unidas Pela Arte (GMUPA) & Mossoró/RN & 2005 & Produção/Urbano \\
\hline $\begin{array}{c}\text { Cooperativa de Mulheres Prestadoras de Serviços } \\
\text { (Coopermups) }\end{array}$ & Mossoró/RN & 2002 & Serviço/Urbano \\
\hline
\end{tabular}

Fonte: dados da pesquisa.

Finalizadas as entrevistas, fez-se necessário transcrever os diálogos para análise com o software Atlas.ti® (versão 5.0), adotando-se os procedimentos ilustrados no Quadro 5. Com a transcrição, foram observados pontos relacionados à identificação das metodologias de custeio e determinação do preço de venda dos EES, bem como o ramo de atuação, peculiaridades e dificuldades enfrentadas. Destaca-se que, como os mesmos não disponibilizaram seus documentos para a triangulação, considerou-se as respostas obtidas entre os entrevistados de cada empreendimento e as informações registradas em seus respectivos Portais, na internet. 
Revista Ambiente Contábil - ISSN 2176-9036 - UFRN - Natal-RN. v. 8. n. 1, p. 76 - 92, jan./jun. 2016

Quadro 5 - Procedimentos utilizados

\begin{tabular}{|l|l|}
\hline PROCEDIMENTO & \multicolumn{1}{c|}{ FINALIDADE } \\
\hline Etapa I & Quebra dos dados (segmentação de partes do texto). \\
\hline Etapa II & Conceituação (a partir de comparações teóricas). \\
\hline Etapa III & Categorização. \\
\hline
\end{tabular}

Fonte: Adaptado de Maciel (2011).

Na primeira etapa procedeu-se com a análise da entrevista transcrita, ou seja, a "leitura cuidadosa e contextualizada de uma linha por vez e na sequência a consideração da linha completa, de uma parte e em alguns momentos de uma palavra para atribuição (conceituação) de um nome de código que refletisse o texto segmentado" (MACIEL, 2011, p. 95). Dessa forma, cada elemento textual foi codificado (quotation). Posteriormente trabalhou-se na perspectiva de classificação e codificação dos achados, organizados por famílias e grupos de famílias. Isso permitiu agrupar as categorias em função das definições, propriedades e dimensões obtidas.

\section{APRESENTAÇÃO E DISCUSSÃO DOS RESULTADOS 4.1 CONTEXTUALIZAÇÃO SOBRE OS EES}

Os EES contemplados no presente estudo se situam no Bairro Nova Vida, no Município de Mossoró/RN: Acrevi, Coopermups e GMUPA. A escolha por esses empreendimentos considerou o esforço individual de cada um deles quanto a geração de renda, emancipação e consolidação de pessoas marginalizadas do mercado, cujos objetivos estão apresentados no Quadro 6.

\begin{tabular}{|c|c|}
\multicolumn{2}{l|}{ Quadro 6 - Propósito dos EES } \\
\hline EES & \multicolumn{1}{c|}{ OBJETIVOS } \\
\hline \multirow{2}{*}{ Acrevi } & $\begin{array}{l}\text { - Contribuir para o equilíbrio do meio ambiente, através de ações concretas voltadas para a } \\
\text { diminuição do impacto dos resíduos sólidos na cidade de Mossoró; } \\
\text { - Gerar renda e melhorar a qualidade de vida de mulheres e homens a partir da coleta seletiva, } \\
\text { reutilização e reciclagem do lixo; } \\
\text { - Desenvolver ações educativas voltadas para o respeito ao ser humano e ao meio ambiente. }\end{array}$ \\
\hline Coopermups & $\begin{array}{l}\text { - Inserir no mercado de trabalho o maior número de mulheres-cooperadas, visando aumentar } \\
\text { sua autoestima e o desenvolvimento de sua capacidade crítica no âmbito econômico, } \\
\text { político, social e cultural. }\end{array}$ \\
\hline GMUPA & $\begin{array}{l}\text { - Gerar renda coletiva por meio da realização de atividades voltadas ao desenvolvimento } \\
\text { artístico, bem como manter os jovens longe das drogas e de influências negativas. }\end{array}$ \\
\hline
\end{tabular}

Fonte: Adaptado do Portal da Acrevi, GMA e GMUPA (2014).

No que diz respeito ao surgimento desses empreendimentos, destaca-se que os mesmos possuem aspectos e desafios em comum, principalmente no que diz respeito à promoção de práticas associadas às premissas da Ecosol, como observado na Figura 1. Nessa conjuntura, a sua constituição possui relação direta com a necessidade de se buscar novas alternativas de atuação profissional, em face do desemprego. Frisa-se, ainda, a motivação social e financeira, com foco no desenvolvimento dos integrantes dos EES e na possibilidade de lhes gerar uma alternativa de renda. 
Figura 1 - Rede que trata do surgimento e dos desafios nos EES estudados.

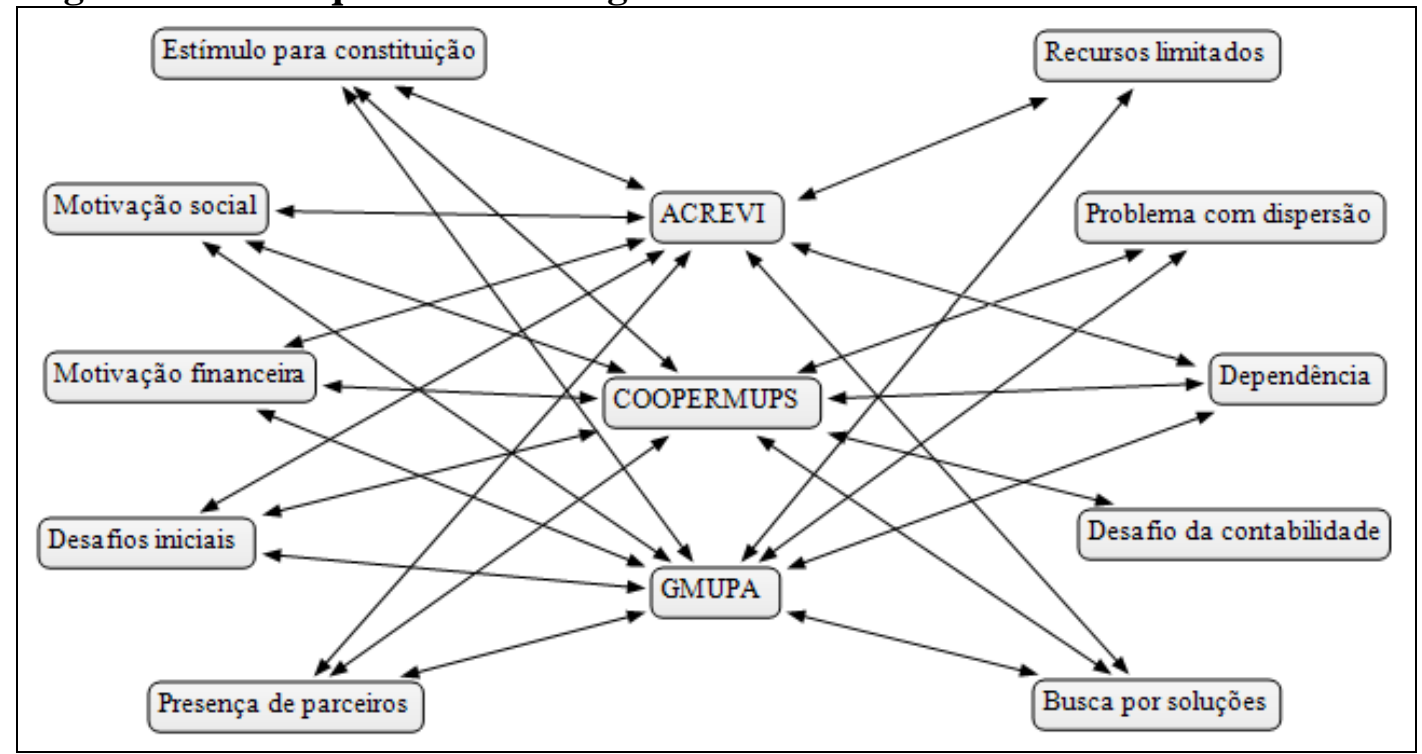

Fonte: dados da pesquisa.

Ademais, todas as entidades de interesse social apontaram a necessidade de apoio de parceiros e indivíduos interessados em sua constituição como medidas essenciais para a sua capacitação e consolidação de suas atividades. Destaca-se que as mesmas ocorreram mediante o fornecimento de recursos financeiro ou de pessoal devidamente preparado. No que concerne os desafios enfrentados pelos EES, constatou-se algumas peculiaridades:

- Acrevi: limitação de recursos e dependência da atuação de parceiros em suas atividades, impedindo a geração de melhorias no ambiente de trabalho;

- Coopermups: dispersão das cooperadas, dependência estrutural do Grupo de Mulheres em Ação e falta de orientações quanto aos fatos contábeis, impactando no não atendimento da demanda e em problemas advindos com a falta de recolhimento de tributos, como o Imposto sobre serviços (ISS).

- GMUPA: possui recursos limitados para financiar os projetos destinados às mulheres que se encontram à margem da sociedade e que vivem em comunidades da zona rural do Município de Mossoró.

\subsection{PROCESSO PRODUTIVO DOS EES}

Acerca do processo de produção, destaca-se que os gestores podem reunir informações pertinentes aos custos dos produtos e serviços oferecidos, de modo a indicar em que momento as práticas de controle devem ser adotadas. Nessa perspectiva, Miqueletto (2008) aponta que a ação dos métodos de custeio se direciona ao processo produtivo e permite identificar os gastos a ele inerentes. Considerando os fatores enumerados, a(o):

- Acrevi: desenvolve atividades relacionadas ao recolhimento e separação de resíduos descartados por pessoas físicas e jurídicas. Os materiais coletados são utilizados para a atividade de reciclagem (papéis, vidros, plásticos e metais) e o empreendimento conta com associados que atuam tanto na equipe de gerência quanto no processo de produção;

- Coopermups: atua em duas frentes de serviço, uma voltada à alimentação (Buffet) e outra à limpeza doméstica. 
- GMUPA: elaboram produtos artesanais personalizados voltados à adoção de diversas técnicas de aplicação personalizadas em camisas (pintadas e/ou bordadas), bijuterias, peças de fuxico, decoração, entre outros.

No que diz respeito à venda do material pela Acrevi, observa-se que a mesma só é concretizada depois de analisados os valores que as empresas estão dispostas a pagar, optando por relações de negócio que lhes apresente a melhor proposta financeira. Isso revela que há um comércio injusto, como tratado por Gomes (2003, p. 51), fundamentado na "intermediação comercial especulativa". Destaca-se que $10 \%$ dos recursos obtidos na venda são retidos para cobrir os gastos da entidade e os demais são distribuídos igualmente entre os membros das equipes que atuam nas atividades executadas no dia.

$\mathrm{Na}$ Coopermups, o preço de cada serviço é estabelecido de acordo com o nível de exigência e complexidade inerente a sua execução, como mostrado no Quadro 7. Nesse contexto, ressalta-se que o fluxo produtivo se inicia com a demanda da sociedade, mediante a solicitação de seus serviços. Além disso, o tipo de cardápio e limpeza requeridos no ato da contratação definem a complexidade e fluxo de atividades necessárias para realizar cada serviço.

\begin{tabular}{|c|c|c|}
\hline \multicolumn{3}{|c|}{ Quadro 7 - Serviços oferecidos pela Coopermups } \\
\hline SERVIÇO & NÍVEIS & NATUREZA \\
\hline \multirow{3}{*}{ Alimentação } & Cardápio simples & Entrada e prato principal simples. \\
\hline & Cardápio intermediário & Entrada, prato principal e sobremesa, convencionais. \\
\hline & Cardápio complexo & $\begin{array}{l}\text { Entrada, prato intermediário, prato principal e sobremesas } \\
\text { sofisticadas. }\end{array}$ \\
\hline \multirow{3}{*}{ Limpeza } & Limpeza simples & Limpeza convencional (varrer, retirar a poeira e lavar). \\
\hline & Limpeza intermediária & Limpeza intermediária (varrer, tirar a poeira, lavar e lustrar). \\
\hline & Limpeza complexa & Faxina completa (limpeza do teto, janelas, portas, etc.). \\
\hline
\end{tabular}

Fonte: dados da pesquisa.

Cabe frisar que os valores recebidos por cada serviço são de responsabilidade da cooperativa, que também deve se encarregar de reter os impostos devidos e a taxa de administração (5\%), bem como determinar e compor a remuneração de cada cooperada. Salienta-se que entre os serviços de limpeza o preço é flexível ( $\mathrm{R} \$ 60,00$ a $\mathrm{R} \$ 100,00)$ e que não há parâmetros que embasem esse valor (número de cômodos, metro quadrado, tempo dedicado, atividades de limpeza a serem executadas). Isso revela que inexistem ações capazes de propiciar o controle e planejamento de suas atividades.

O GMUPA atende encomendas programadas de pequena, média e grande escala, além de promoverem eventos. A distribuição das tarefas é realizada de acordo com as aptidões de cada membro, sendo mantida uma pequena produção para atender aos pedidos on-line e à "Feira de Economia Solidária do Bairro Nova Vida". As suas ações e estoques são devidamente programados de acordo com a escala de produção e observando as metas a serem atingidas.

\subsection{METODOLOGIA DE CUSTEIO}

Destaca-se que na área de contabilidade de custos há vários métodos de custeio e que os mesmos podem ser adotados pelas empresas com o intuito de auxiliá-las na prestação de contas e na determinação das práticas gerenciais. Dentre os métodos comumente identificados na literatura, têm-se os custeios por absorção, variável e o ABC. Nessa concepção, a partir das informações repassadas pelos EES analisados, foi possível identificar que os mesmos conhecem as metodologias de custeio e formação do preço de venda, apesar de não os adotar em sua plenitude, como pode ser observado na Figura 2. 
Figura 2 - Rede que trata dos métodos de custeio adotados pelos EES estudados.

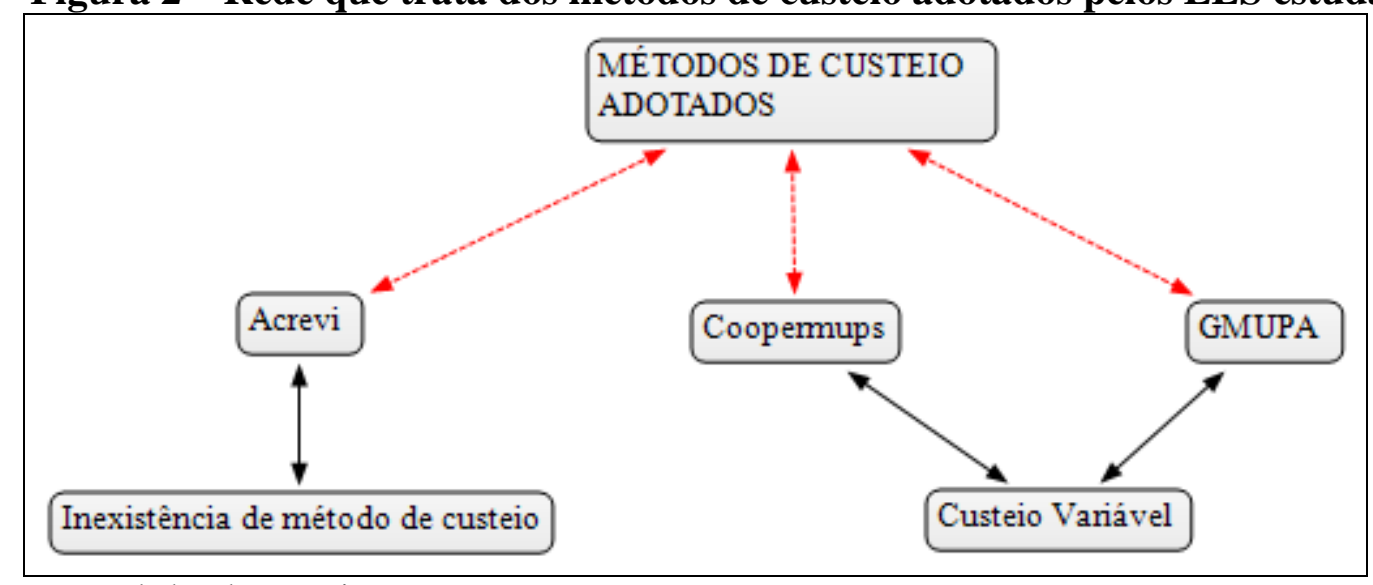

Fonte: dados da pesquisa.

Considerando os aspectos apresentados, salienta-se que a Acrevi não adere a nenhuma metodologia de custeio, revelando que há certa fragilidade na demarcação do preço de venda que está associado aos interesses de compra dos intermediários. Já a Coopermups e o GMUPA, apesar de não deterem conhecimentos contábeis condizentes com o método adotado, utilizam procedimentos que se aproximam ao custeio variável. Tal fato ocorre ao se perceber o tratamento dado à apropriação dos custos variáveis (materiais e mão de obra) em cada tipo de serviço oferecido e produto negociado.

Destaca-se que fatores como as despesas de vendas e administrativas, tributação, custos fixos e margem de lucro não são observados no custeio variável. O estudo revela também que, no caso da cooperativa, não são adotados parâmetros confiáveis para a determinação do valor de mão de obra das cooperadas. No grupo, observa-se a adoção de critérios de rateio dos materiais vinculados ao consumo, ao tempo médio utilizado em cada produto confeccionado e aos gastos inerentes a produção de cada peça.

\subsection{PREÇO DE VENDA}

Com o intuito de compreender como ocorre a formação do preço de venda dos EES pesquisados e os princípios da economia solidária, observou-se que:

- Acrevi: não possui conhecimentos sobre a formação do preço em razão de não adotarem nenhuma prática de gestão. Isso porque, a lógica da comercialização é invertida e quem estabelece o valor pago por quantidade de resíduo é a entidade compradora.

- Coopermups: detém conhecimentos sobre a formação do preço de venda, mas tem dificuldades em adotar um método específico como padrão de demarcação.

- GMUPA: nem todos os associados possuem conhecimentos sobre a formação do preço e cálculo dos custos, cabendo aos detentores desse conhecimento a incorporação dos custos necessários para confecção dos produtos.

Com base nos achados da Acrevi, observa-se que seu comportamento ameaça o desenvolvimento do empreendimento, uma vez que o preço de mercado não segue a lógica da reciprocidade (FRANÇA FILHO, 2007) e vai de encontro com as condições básicas do empreendimento solidário, como pode ser observado na Figura 3. 


\section{Figura 3 - Rede de representação dos elementos atrelados ao preço injusto da Acrevi}

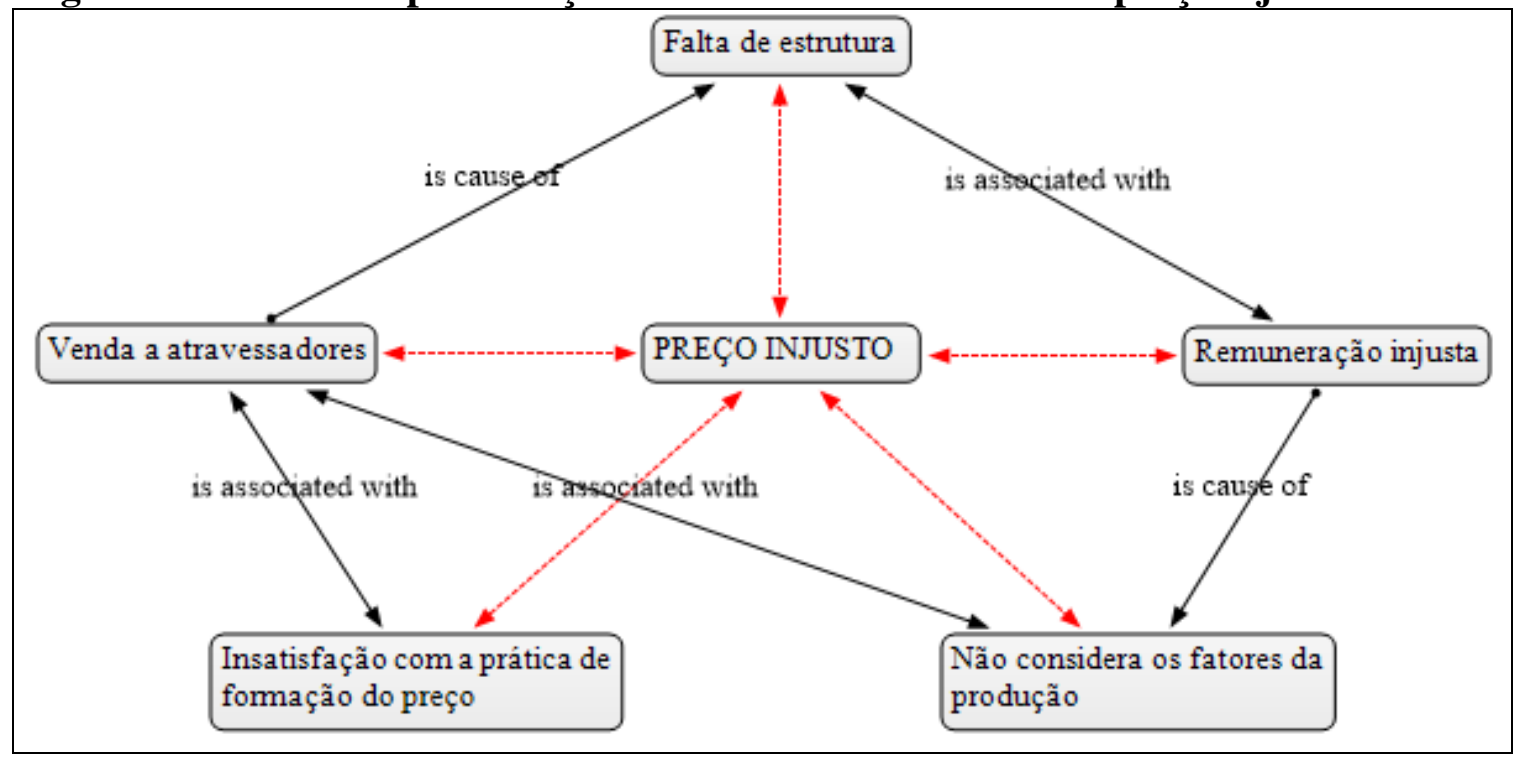

Fonte: dados da pesquisa.

A adoção de algum método de custeio não influenciaria o preço de venda, mas as informações disponibilizadas poderiam reunir elementos que garantiriam a operacionalização da entidade no longo prazo. Nessa perspectiva, seria interessante considerar a agregação de valor aos produtos reciclados, paralelamente a utilização de um preço orientativo (WERNKE, 2008) a ser confrontado com a disponibilidade de pagamento dos atravessadores. Destaca-se também, que o preço injusto está associado à falta de estrutura da entidade e à insatisfação dos associados quanto à remuneração recebida em função da atividade executada.

Na Coopermups, o preço dos serviços de alimentação observa os custos, dos materiais e da mão de obra, necessários para a preparação das refeições. Já o serviço de limpeza, demanda apenas a mão de obra inerente a cada atividade, ficando a critério da cooperada definir o preço do serviço. Considerando esses aspectos, o preço do serviço de alimentação pode ser compreendido como injusto e o de limpeza como justo, quando comparado aos valores praticados no mercado, como pode ser visualizado na Figura 4.

Os dados indicam que a adoção de uma estratégia de gestão de custos é essencial para o processo de tomada de decisão, principalmente ao se considerar os gastos incorridos no processo de produção. Isso porque, os indivíduos envolvidos na Coopermups precisam ter parâmetros que lhes permitam determinar um preço justo para as refeições servidas. Nessa conjuntura, precisa alinhar a disponibilidade do cliente em pagar pelo produto ou serviço negociado com a concessão de uma remuneração mais digna para as cooperadas e disponibilidade de recursos que lhes permitam cobrir as obrigações da cooperativa. 
Revista Ambiente Contábil - ISSN 2176-9036 - UFRN - Natal-RN. v. 8. n. 1, p. 76 - 92, jan./jun. 2016

Figura 4 - Rede de representação dos elementos atrelados ao preço justo e injusto da Coopermups.

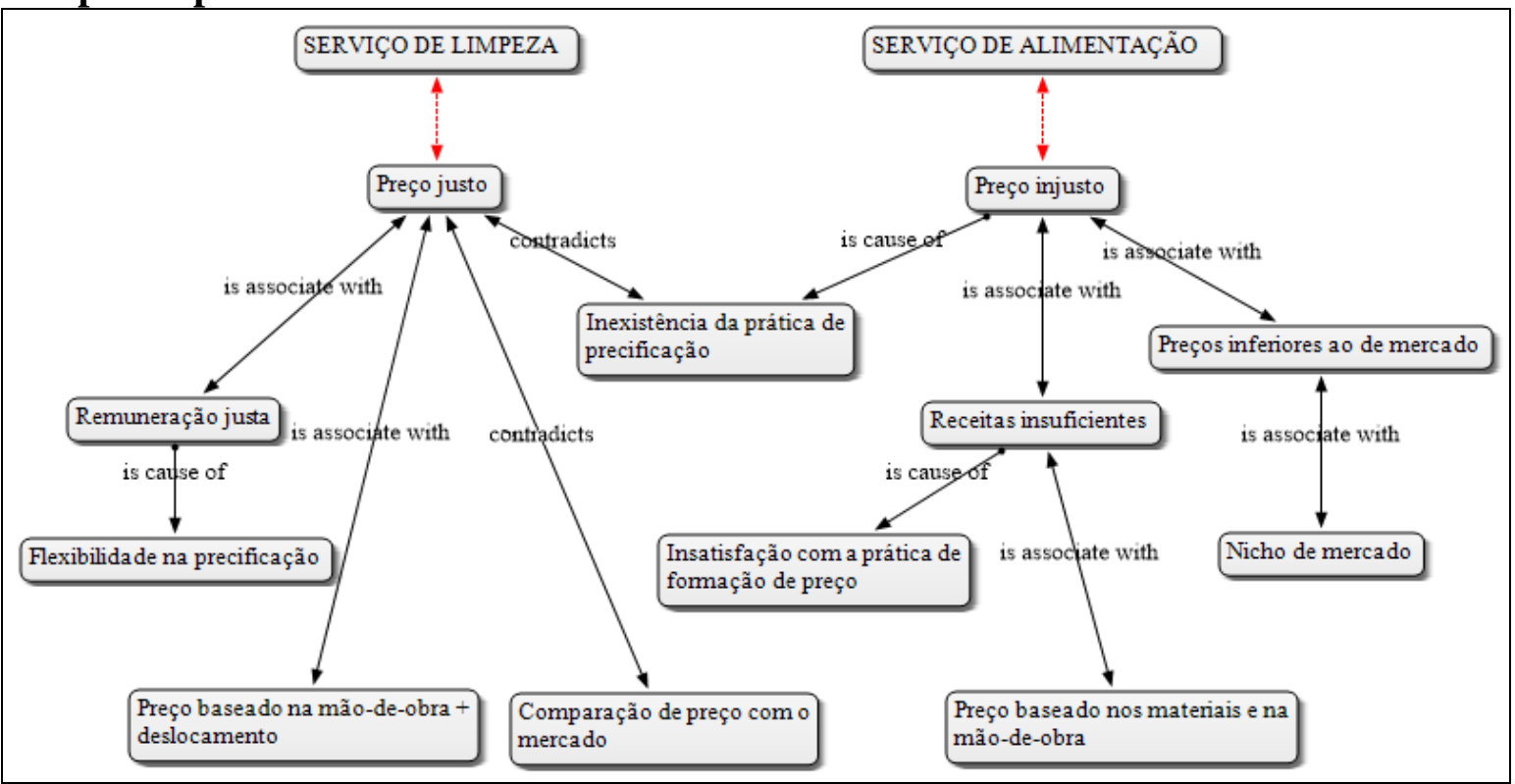

Fonte: dados da pesquisa.

No GMUPA a dificuldade quanto à gestão do preço está relacionada ao rateio dos custos dos materiais aos produtos elaborados. Isso ocorre em razão da dificuldade de seus membros em indicarem quanto de material foi utilizado ou desperdiçado na confecção dos produtos, bem como o tempo despendido e o valor da mão de obra destinados à elaboração de cada peça, como ilustrado na Figura 5.

Figura 5 - Rede de representação dos elementos atrelados ao preço justo do GMUPA.

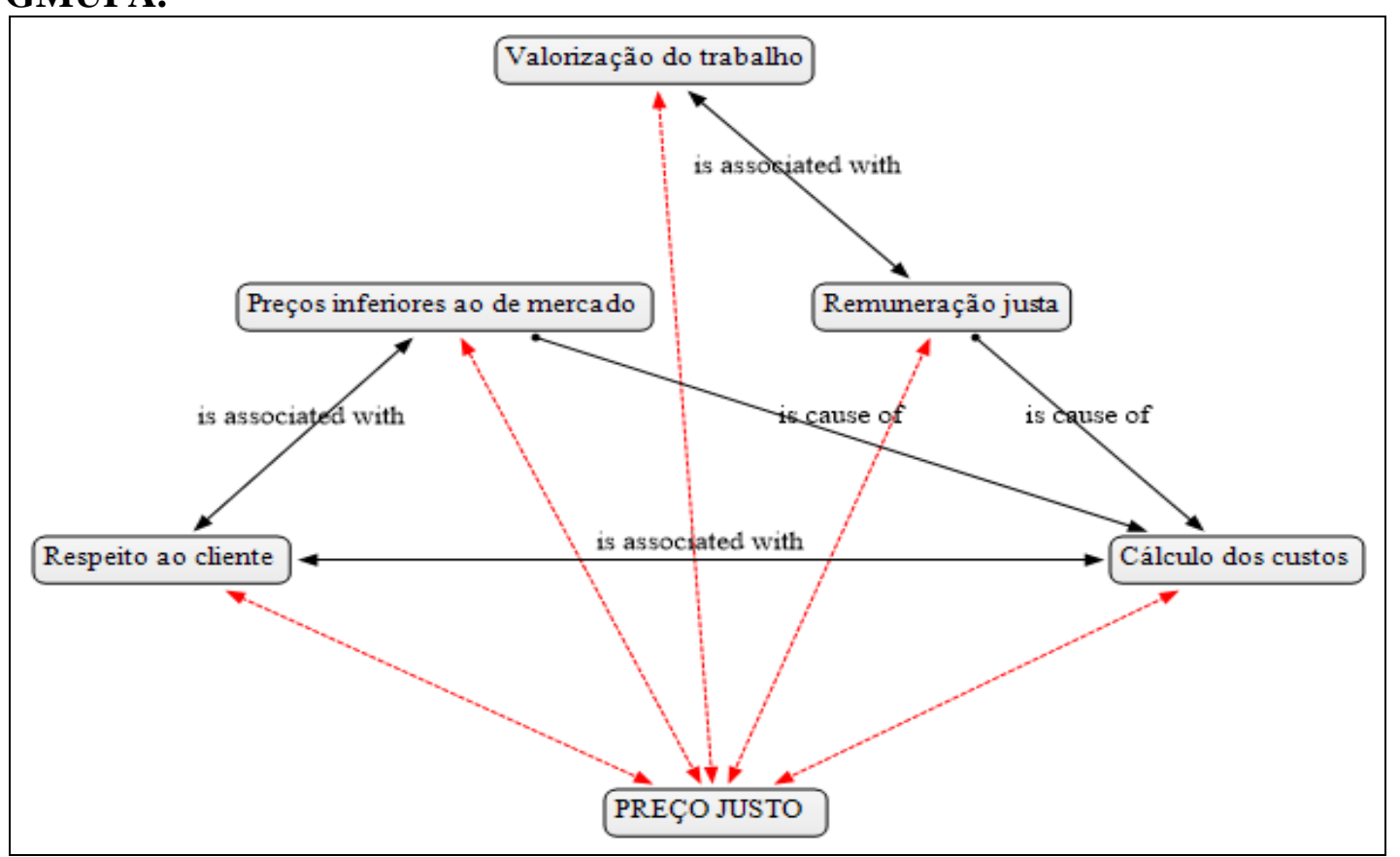

Fonte: dados da pesquisa.

Observa-se que os membros do GMUPA buscam se aproximar ao máximo do valor gasto em cada artigo, desde os materiais utilizados até o tempo de mão de obra destinado. Apesar disso, o valor de cada doação recebida e das despesas de venda não são consideradas 
na determinação do preço. Nessa perspectiva, o grupo segue ao que preceitua o custeio variável, uma vez que associa os custos variáveis às peças confeccionadas, estando os custos fixos e encargos financeiros tratados como despesas.

Os achados revelam que é possível reconhecer as práticas de gestão de preço dos EES e os procedimentos adotados para a sua formação. Nessa perspectiva, destaca-se que a Acrevi não se utiliza dos dados que dispõe para subsidiar a gestão dos custos e a formação do preço de venda. No que diz respeito à composição dos custos na Coopermups e no GMUPA, observa-se que ambos adotam a quantidade de materiais utilizados na composição de seus custos como parâmetro. A mão de obra direta e indireta observa o valor pago, a cargo de remuneração, porém somente o GMUPA utiliza o tempo dedicado à produção como critério de valoração.

Considerando os fatos expostos, salienta-se que as decisões quanto ao preço de venda da Coopermups e do GMUPA precisam incluir aspectos como: custos fixos, encargos, depreciação e despesas de venda. Nesse sentido, a prática adotada para demarcação do preço justo está vinculada apenas a gestão da mão de obra (direta e indireta), matéria-prima e materiais indiretos, em função dos elementos consumidos na produção. Frente ao que foi evidenciado, constata-se que as práticas gerenciais intrínsecas aos conceitos de custos e formação de preços, tratados pela literatura, não estão sendo adotados pelos EES analisados.

\section{CONSIDERAÇÕES FINAIS}

O estudo objetivou identificar as metodologias de custeio e preço de venda, adotadas pelos EES de Mossoró/RN, para a formação do preço justo de seus produtos e serviços. Para isso, foram realizadas entrevistas com os membros das equipes de gestão de três EES. Os referidos empreendimentos surgiram com o suporte financeiro e social de alguns parceiros e instituidores, com o intuito de propiciar o desenvolvimento social e comunitário mediante a adoção de ações educativas e busca por alternativas de renda.

Em relação aos métodos de custeio, destaca-se que a Acrevi não adere aos preceitos das metodologias tradicionais. Já a Coopermups e o GMUPA adotam aspectos que se assemelham a metodologia do custeio variável, apropriando os custos variáveis existentes (materiais e mão de obra) aos serviços oferecidos e produtos elaborados. Apesar disso, os mesmos não se preocupam em destinar parte de seus recursos para cobrir gastos com custos fixos, encargos, depreciação e despesas de venda.

Quando se trata do preço de venda dos produtos e serviços, observa-se que a Coopermups e o GMUPA o determinam com base nos materiais consumidos e na mão de obra empregada. Para tanto, a GMUPA adota o tempo como um balizador do preço, ao contrário da Coopermups, que não se utiliza de nenhum tipo de parâmetro para guiar essa determinação. A Acrevi, em função de sua particularidade, não emprega nenhuma metodologia específica.

Observando a situação dos EES estudados, destaca-se que as metodologias de custeio são pouco utilizadas ao se considerar a relação de custo-benefício da informação. Apesar disso, enfatiza-se que é importante adotar metodologias de custeio economicamente viáveis, capazes de garantir o adequado gerenciamento dos recursos e subsidiar a tomada de decisão. A inexistência de gestão tem gerado problemas quanto à viabilidade do empreendimento, bem como a determinação do preço com base nos custos e despesas incorridas.

Salienta-se que a essência dos métodos contribui para a formação do preço de venda, apesar de efetivamente não cobrir todas as obrigações da entidade e gerar sobras. Nessa perspectiva, embora os membros declarem ter acesso a cursos relacionados às metodologias de custeio e formação do preço de venda, os mesmos têm dificuldades em colocá-los em 
Revista Ambiente Contábil - ISSN 2176-9036 - UFRN - Natal-RN. v. 8. n. 1, p. 76 - 92, jan./jun. 2016

prática. Logo, as estratégias de gerenciamento dos EES precisam ser constantemente alinhadas.

Por fim, percebe-se que os EES estudados têm dificuldades em reconhecer, entre suas ações, as prerrogativas do preço justo. Nessa perspectiva, a Coopermups e o GMUPA demarcam o seu preço considerando apenas três elementos: mão de obra, matéria-prima e materiais indiretos. Já a Acrevi, revela que não adota nenhuma prática ou estratégia de ação que lhe permita determinar o preço justo.

Considerando os achados do estudo, recomenda-se a realização de um levantamento capaz de mapear o comportamento dos EES quanto ao preço justo. Sugere-se também a criação de um instrumento de coleta apropriado para avaliar os métodos de custeio existentes e as condições do empreendimento. Além disso, recomenda-se o uso da abordagem quantitativa para medir a percepção dos respondentes quanto às metodologias de custeio tradicionais e formação do preço de venda.

\section{REFERÊNCIAS}

ACREVI. Associação Comunitária Reciclando para a Vida. Voluntariado em gestão. Disponível em: <http://acrevi.blogspot.com.br/>. Acesso em: 13 jan. 2014.

ASTI, A. L. Comércio Justo e o Caso do Algodão: a cadeia produtiva têxtil brasileira. 2007. 238 f. Dissertação (Mestrado em Ciências Sociais) - Universidade Federal Rural do Rio de Janeiro, Rio de Janeiro, 2007.

BEULKE, R.; BERTÓ, J. R. Gestão de Custos. 1. ed. São Paulo: Saraiva, 2006.

BRUNI, A. L.; FAMÁ, R. Gestão de Custos e Formação de Preço. 2. ed. São Paulo: Atlas, 2003.

CANEVER, F. P.; LUNKES, R. J.; SCHNORRENBERGER, D.; GASPARETTO, V. Formação de Preços: um estudo em empresas industriais de Santa Catarina. Revista de Contabilidade do Mestrado em Ciências Contábeis da UERJ (online), Rio de Janeiro, v. 17, n. 2, p. 15-27, maio/ago. 2012.

CFC. Conselho Federal de Contabilidade. Resolução n. ${ }^{\circ}$ 1.282, de 28 de janeiro de 2010. Atualiza e consolida dispositivos da Resolução CFC n. ${ }^{\circ}$ 750/93, que dispõe sobre os Princípios Fundamentais de Contabilidade. Resolução CFC N. 1.282/10. Disponível em: <http://www.normaslegais.com.br/legislacao/respcaocfc1282_2010.htm>. Acesso em: 15 nov. 2013.

CREPALDI, S. A. Curso Básico de Contabilidade de Custos. 4. ed. São Paulo: Atlas, 2009.

CULTI, M. N.; KOYAMA, M. A. H.; TRINDADE, M. Economia Solidária no Brasil: tipologia dos Empreendimentos Econômicos Solidários. São Paulo: Todos os Bichos, 2010.

DIAS, T. F. Gestão Social em Empreendimentos Econômicos Solidários: uma abordagem no Oeste Potiguar. 2011. 230 f. Tese (Doutorado em Administração) - Universidade Federal do Rio Grande do Norte, Natal, 2011.

DIAS, T. F.; SOUZA, W. J. Idas e Vindas: do socialismo utópico à Economia Solidária. In: Encontro Nacional de Pesquisadores em Gestão Social, 3, 2009, Juazeiro-Petrolina. Anais... Juazeiro-Petrolina: UNIVASF, 2009.

FBES. Fórum Brasileiro de Economia Solidária. Carta de Princípios da Economia Solidária. III Plenária de Nacional da Economia Solidária, 2003. Disponível em: <http://www.fbes.org.br/index.php?option=com_content\&task=view\&id=63\&Itemid=60>. Acesso em: 15 jul. 2013. 
Revista Ambiente Contábil - ISSN 2176-9036 - UFRN - Natal-RN. v. 8. n. 1, p. 76 - 92, jan./jun. 2016

FRANÇA FILHO, G. C. Novos Arranjos Organizacionais Possíveis? O Fenômeno da Economia Solidária em Questão (Precisões e Complementos). Organizações \& Sociedade, Salvador, v. 8, n. 20, p.1-14, jun./jul.2001.

FRANÇA FILHO, G. C. Teoria e Prática em Economia Solidária: Problemática, Desafios e Vocação. Civitas, Porto Alegre, v. 7, n. 1, p.155-174, jan./jun. 2007.

GAIGER, L. I. G. A Economia Solidária Diante do Modo de Produção Capitalista. Caderno CRH, Salvador, v. 30, n. 39, p.181-211, jul./dez.2003.

GARRISON, R. H.; NOREEN, E. W.; BREWER, P. C. Contabilidade Gerencial. 11. ed. Rio de Janeiro: LTC, 2007.

GMA. Grupo de Mulheres em Ação. Mulheres em Ação. Disponível em: <http://pdamargaridaalves.blogspot.com.br/p/grupo-mulheres-em-acao.html>. Acesso em: 11 jan. 2014.

GMUPA. Grupo de Mulheres Unidas pela Arte. Unidas pela arte. Disponível em: $<$ http://grupounidaspelaarte.blogspot.com.br/2012/06/grupo-unidas-pela-arte-se-reunitodas.html>. Acesso em: 11 Jan. 2014.

GOMES, R. Comércio Justo: entre a solidariedade e a utopia. Proposta, Rio de Janeiro, v. 10, n. 98, p.46-55, nov. 2003.

HORNGREN, C. T.; DATAR, S. M.; FOSTER, G. Contabilidade de Custos. 11. ed. São Paulo: Pearson, 2004.

KOTLER, P.; KELLER, K. L. Administração de Marketing: a bíblia do marketing. 12. ed. São Paulo: Pearson, 2006.

LISBOA, A. M. Economia Solidária e Autogestão: imprecisões e limites. Revista de Administração de Empresas, São Paulo, v. 45, n. 3, p.109-115, mai. 2005.

MACHADO, D. G.; SOUZA, M. A. Análise das Relações Entre a Gestão de Custos e a Gestão do Preço de Venda: um estudo das práticas adotadas por empresas industriais conserveiras estabelecidas no RS. Revista Universo Contábil, Blumenau, v. 2, n. 1, p. 42-60, jan./abr. 2006.

MACIEL, C. O. Teoria da Dotação Social Estratégica: uma explicação sobre a construção social de estratégias e seus praticantes em setores emergentes da internet. 2011. $184 \mathrm{f}$. Tese (Doutorado em Administração) - Pontifícia Universidade Católica do Paraná, Curitiba, 2011.

MAHER, M. Contabilidade de Custos: criando valor para a administração. São Paulo: Atlas, 2001.

MARTINS, E. Contabilidade de Custos. 9. ed. São Paulo: Atlas, 2003.

MIQUELETTO, E. M. Formação do Preço de Venda: uma análise do processo de formação de preço em empresas madeireiras de grande porte de Curitiba e Região Metropolitana. 2008. 103 f. Dissertação (Mestrado em Ciências Contábeis) - Universidade Federal do Paraná, Curitiba, 2008.

MOTTA, F. G. Fatores Condicionantes na Adoção de Métodos de Custeio em Pequenas Empresas: estudo multicasos em empresas do setor metal-mecânico de São Carlos/SP. 2000. 205 f. Dissertação (Mestrado em Engenharia de Produção) - Universidade de São Paulo, São Carlos, 2000. 
OLIVEIRA, R. F.; ARAÚJO, U. P.; SANTOS, A. C. Efeito do Fair Trade na Cooperativa de Agricultores Familiares de Café de Poço Fundo, MG. Organizações Rurais \& Agroindustriais, Lavras, v. 10, n. 2, p. 211-225, ago. 2008.

PEREIRA, F. H. Metodologia de Formação de Preço de Venda para Micros e Pequenas Empresas. 2000. 159 f. Dissertação (Mestrado) - Universidade Federal De Santa Catarina, Florianópolis, 2000.

PEREZ JÚNIOR, J. H.; OLIVEIRA, L. M.; COSTA, R. G. Gestão estratégica de custos. 3. ed. São Paulo: Atlas, 2003.

SANTOS, E.; MARIANO, J.; PASSANEZI, P. Entrevista com Paul Singer. Revista Gerenciais, São Paulo, v. 2, n. 5, p.3-5, set. 2003.

SCHMITT, C. J. Economia Solidária e Agroecologia: convergências e desafios na construção de modos de vida sustentáveis. Mercado de Trabalho, Rio de Janeiro, v. 8, n. 42, p. 55-64, fev. 2010.

SENAES-SIES. Atlas da Economia Solidária 2005-2007. São Paulo: Todos os Bichos/ANTEAG, 2009. Disponível em: <http://consulta.mte.gov.br/atlas/AtlasES.html>. Acesso em: 12 jul. 2013.

SILVA, E. L.; MENEZES, E. M. Metodologia da Pesquisa e Elaboração de Dissertação. 4. ed. Florianópolis: UFSC, 2005.

SINGER, P. Introdução à Economia Solidária. São Paulo: Editora Fundação Perseu Abramo, 2002.

VERENHITACH, G. D. Comércio Justo: o Terceiro Setor como ator social na consolidação de práticas alternativas de comércio. In: Seminário Nacional de Movimentos Sociais, Participação e Democracia, 2, 2007, Florianópolis. Anais... Florianópolis: Núcleo de Pesquisa em Movimentos Sociais (NPMS), 2007.

VERONESE, M. V.; GUARESCHI, P. Possibilidades Solidárias e Emancipatórias do Trabalho: campo fértil para a prática da psicologia social crítica. Psicologia \& Sociedade, Belo Horizonte, v. 2, n. 17, p. 58-69, maio/ago.2005.

WERNKE, R. Gestão de Custos: Uma Abordagem Prática. 2. ed. São Paulo: Atlas, 2008. 